\title{
DISSIPATION OF ENERGY IN SANDWICH-STRUCTURED EQUESTRIAN HELMET - NUMERICAL ANALYSIS UNDER OVERLOAD CONDITIONS
}

doi: 10.2478/czoto-2021-0002

Date of submission of the article to the Editor: $06 / 12 / 2020$

Date of acceptance of the article by the Editor: 01/03/2021

\author{
Natalia Bińczak ${ }^{1}$ - orcid id: 0000-0002-8718-6340 \\ Piotr Kuryło ${ }^{1}$ - orcid id: 0000-0001-9820-1254 \\ 'University of Zielona Góra, Poland
}

\begin{abstract}
Protection of the head structures is a requirement in many sports where a person is exposed to injuries that threaten life or health. In horse riding accidents occur often, resulting in serious head injuries. The analysis of the available literature shows that the helmets used now protect human head structures in a small percentage. The aim of the research was to analyze the degree of protection of the human head using available helmet structure and a new solution for the Energy absorbing layer in helmet that absorbs Energy from impacts. The research was divided into two stages. During the first one, a simulation was performer under dynamic conditions simulating the rider's fall and the contact of the head with ground (impact from the side). In the second stage, three structures of the absorbing layers were developed, i.e. honeycomb, auxetic, mixed with three three wall thicknesses (1 $\mathrm{mm}, 2 \mathrm{~mm}$ and $3 \mathrm{~mm}$ respectively) and two materials were used: the currently used EPS and the aluminium alloy used in the motorcycle helmet.
\end{abstract}

Keywords: head injuries, equestrian helmet, honeycomb

\section{INTRODUCTION}

Equestrian - Related Injuries (ERIs) mostly involve human's head, neck and spine but also fractures of the limbs and injuries to the chest. In 2018, an analysis of 7,815 riding-related injuries in Sweden was conducted (Meredith et al., 2018). Among all reported persosn $19,2 \%$ of riders suffered head injuries. $56,3 \%$ of those injuries involved soft tissue, 33,4\% - concussions, 7,9\% - fractures or dislocations. The remaining injuries involved tears of the jaw muscles or craniofacial injuries (nose fracture, injuries to the lips and mouth). The most common brain injuries include: intracranial hematoma, subdural hematoma and intracerebral hematoma. Due to the high risk of head injuries that could endanger the health and life of riders it is required to protective helmets that must meet safety standards (Europe - EN 1384 and EN 14572). In many equestrian disciplines lack of a helmet at competitions disqualifies 
the competitor and for recreational riding are determined by the stud (people under 18 have to wear helmet).

Currently used helmets are designed to protect the head against injuries caused by sharp objects and to absorb the energy generated as a result of an impact. The construction of riding helmets consists of three layers: the outermost one is rigid, thin shell; the innermost one is a lining that ensures comfort while using; between them is an energy - absorbing layer. During an impact, the filling in the helmet is deformed so the helmet should be replaced after the slightest impact. The deformed layer does not fullfil its task. The most commonly used material for the outer coating is ABS (acrylonitrile butadiene styrene copolymer). Acrylonitrile is responsible for the increased mechanical and chemical resistance of the material, styren eis responsible for strength and quality, polybutadiene rubber provides high impact strength and resistance to dynamic loads. The damping layer is usually made of EPS material (expanded polystyrene). It provides shock resistance and vibration reduction. The last layer is a lining, usually made of velvet, which makes the helmet comfortable to use. Some helmets have a layer of rubber or leather on the outside of the helmet for an aesthetic function.

\section{METHODOLOGY}

The research was divided into two stages in which dynamic load analysis was applied using Ansys 16.2 Workbench Explicit Dynamics. In the first stage a simple helmet model was created based on structures available on the market. The test models were developed in Solidworks. The model of the helmet was made of three layers: a rigid outer layer made of ABS material, a damping layer made of EPS foam and an inner boundary layer made of velvet. The human head model contained such structures as skull, brain, meninges and cerebrospinal fluid. Material parameters were assigned to individual model elements in Ansys 16.2 Workbench and are presented in table 1.

Table 1

Parameters of structures of model



Source: (Kleiven, 2009; Caserta, 2012) 
The rider's center of gravity while riding a horse can be estimated at height of about 2 meters above the ground. A direct downward fall from a horse occurs at a speed of $6 \mathrm{~m} / \mathrm{s}$ in the case of a horse walking calmly. For a galloping horse, the fall speed is increased by an additional $12 \mathrm{~m} / \mathrm{s}$. In the tests, the speed was declared at $6,3 \mathrm{~m} / \mathrm{s}$ and a load of $5 \mathrm{kN}$ was applied at $650 \mathrm{~ms}$ (Bourdet and Willinger, 2015). The calculation was completed at 1 second. BONDED linear contacts were used between the physiological structures in the model, while ROUGH contacts were used between the skull and the helmet. The second stage of research was to develop simple models (cubes) that were the segment of an equestrian helmet, skull, meninges and brain. 10 geometric models were developed. In 9, the geometry of the damping layer (honeycomb, auxetic, honeycomb - auxetic), materials from which they were made (EPS and aluminium alloy) and the wall thickness of the geometric elements of the core structures were changed.

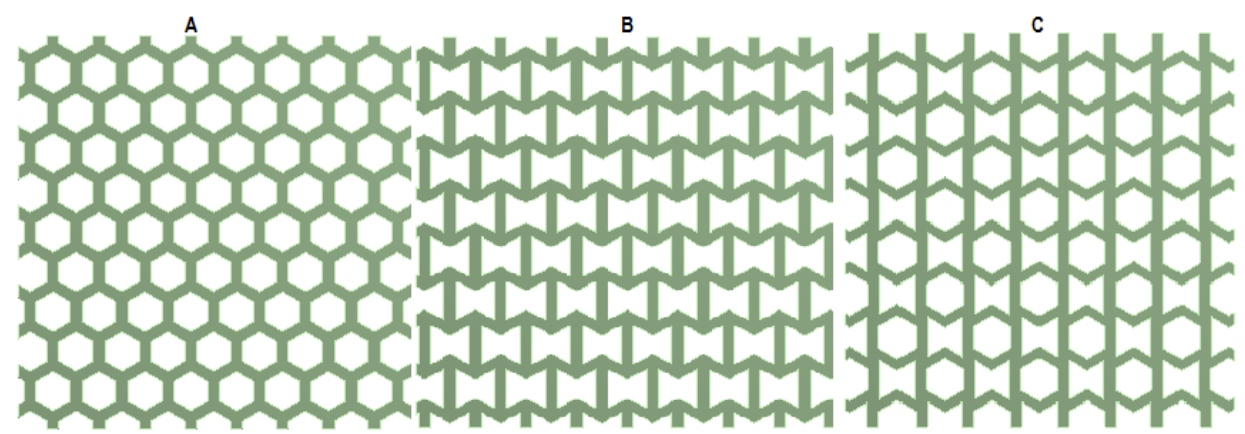

Fig. 1. Models' core structures: A - honeycomb, B - auxetic, C - honeycomb - auxetic

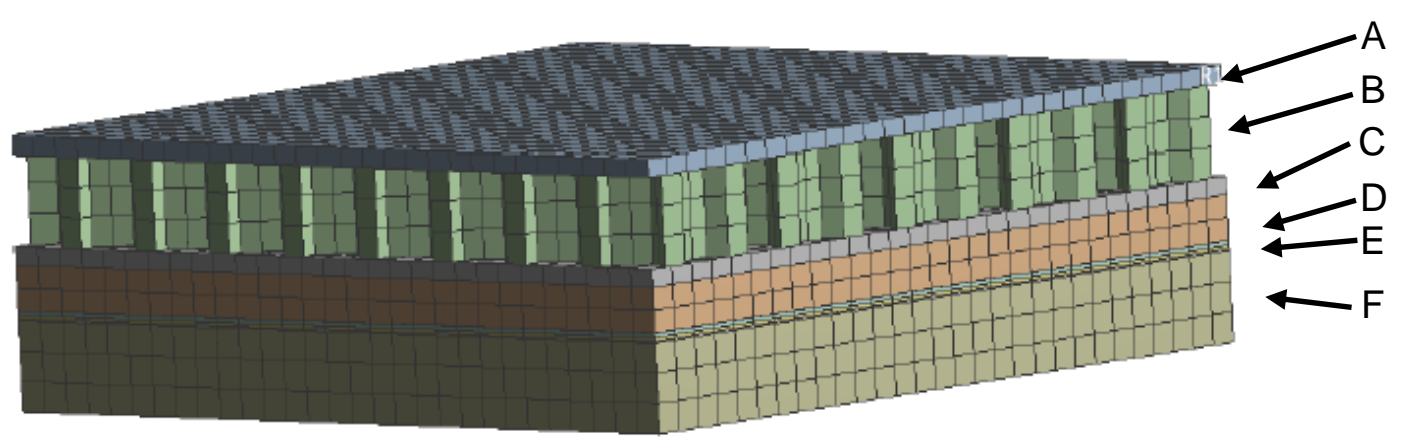

Fig. 2. Sample of cube model: A - rigid outer layer, B - energy absorbing layer, C - inner boundary layer, D - skull, E - meninges, F - brain

Figure 1 shows the example of structures of Energy absorbing layers and figure 2 shows cube used in second stage of the research. Table 2 shows pamareters of materials used in analysis.

Table 2

Mechanical properties of energy absorbing layers

\begin{tabular}{|l|l|}
\hline Energy absorbing layer & Material data \\
\hline EPS & $\rho=50 \mathrm{~kg} / \mathrm{m}^{3}, E=27.1 \mathrm{MPa}, \mathrm{v}=0.01$, thickness: $10 \mathrm{~mm}$ \\
\hline Aluminium - based material & $\rho=2730 \mathrm{~kg} / \mathrm{m}^{3}, \mathrm{E}=68.9 \mathrm{GPa}, \mathrm{v}=0.33$, thickness: $10 \mathrm{~mm}$ \\
\hline
\end{tabular}

Source: (Caserta, 2013) 


\section{RESULTS}

The result of the first simulations was the distribution of stress and deformstions in brain structures, which resulted from the rider falling off the horse and hitting the ground with the side part of the head. The obtained values of stress did not exceed $5,06 \mathrm{MPa}$ but it is the value that causes brain damage. Accodring to the literaturę data presented in the table 3 , stress values that do not damag the brain do not exceed 10 $\mathrm{kPa}$.

Table 3

Stress values affecting the brain

\begin{tabular}{|l|}
\hline Values of stress damaginf brain \\
\hline$\geq 11 \mathrm{kPa}-$ brain damage (car accident) \\
\hline$>7-8.6 \mathrm{kPa}-$ injury \\
\hline $220 \mathrm{kPa}-$ mild brain trauma \\
\hline $15-20 \mathrm{kPa}-$ trauma - concussion \\
$>27 \mathrm{kPa}-50 \%$ probability of moderate failure \\
$>39 \mathrm{kPa}-50 \%$ probability od severe damage \\
$>18 \mathrm{kPa}-50 \%$ probability od moderate neurological changes \\
$>38 \mathrm{kPa}-50 \%$ probability of severe neurological changes \\
\hline $226 \mathrm{kPa}-$ axonal damage
\end{tabular}

Source: (Zhou et al., 1995; Miller et al., 2002; Newman, 1986; Willinger and Baumgartner, 2003, 2005; Baumgartner et al., 2001; Deck and Willinger, 2008)

Obrained strain values did not exceed the value of $1,1 \mathrm{~mm} / \mathrm{mm}$ which indicates brain damage according to the literature wich indicates that brain injuries start from the value of about $0,15 \mathrm{~mm} / \mathrm{mm}$. Literature data was shown in table 4 .

Table 4

Strain values affecting the brain

\begin{tabular}{|l|}
\hline Values of strain causing brain damage \\
\hline $0,25-$ structural brain damage \\
$>0,20$ - brain dysfunction \\
$<0,10$ - reversible brain damage \\
\hline$>0,188-$ formation of hematomas \\
\hline$>0,14-25 \%$ probability of mild brain injury \\
$>0,19-50 \%$ probability of mild brain injury \\
$>0,24-80 \%$ probability of mild brain injury \\
\hline$\geq 0,18-$ axonal trauma \\
\hline
\end{tabular}

Source: (Galbraith et al., 1993; Shreiber et al., 1997; Zheng et al., 2004; Deck and Willinger, 2008)

Thanks to the first simulation it was possible to obtain information about lack of protection of the currently used equestrian helmets. Therefore, the second stage of research was carried out to illustrate the possibility of using a different structure of the damping layer, which would improve the protection of the head structures.

Figures $4-7$ shows the stress and strain values of chosen structures: currently used layer made of EPS, honeycomb structures (thickness of the walls of cells $-1 \mathrm{~mm}$ ) 
made of EPS and aluminium based material, auxetic structure (thickness of the walls of cells $-1 \mathrm{~mm}$ ) made of EPS and aluminium based material.


Fig. 3. Stress and strain values for the currently used energy absorbing layer structure made of EPS


Fig. 3. Stress and strain values of honeycomb structure (1 $\mathrm{mm}$ thickness, made of EPS)
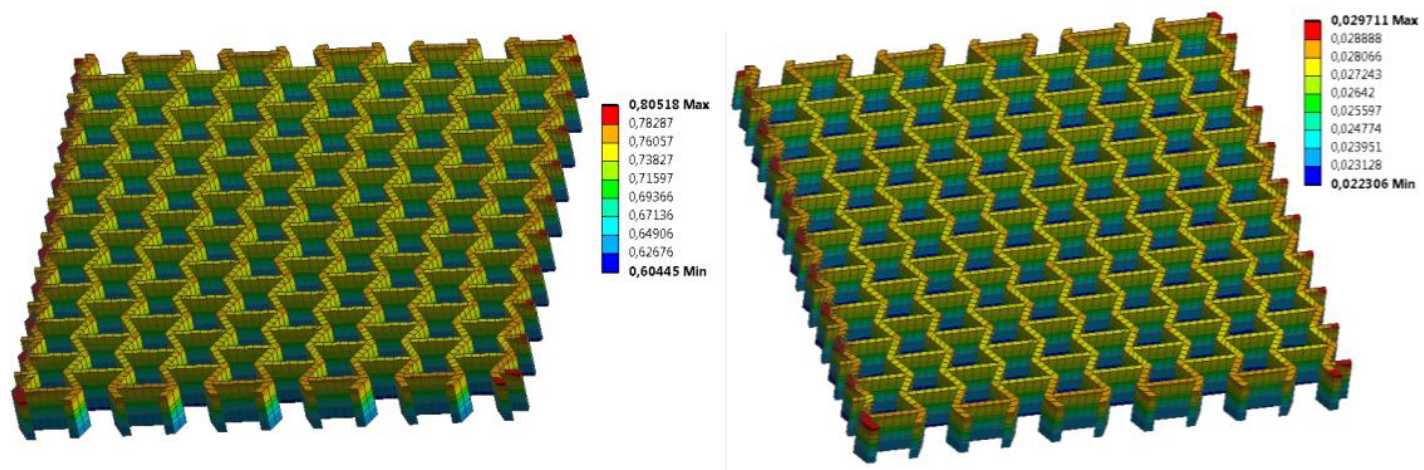

Fig. 4. Stress and strain values of auxetic structure (1 $\mathrm{mm}$ thickness, made of EPS) 

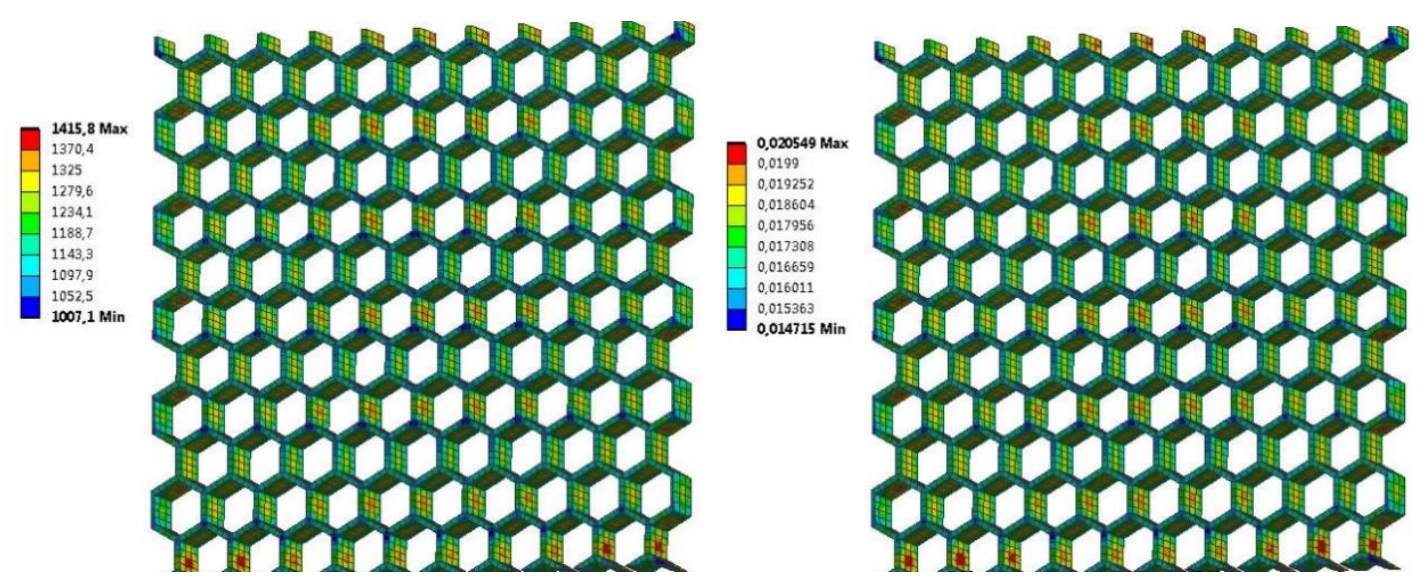

Fig. 5. Stress and strain values of honeycomb structures $(1 \mathrm{~mm}$ thickness, made of aluminium - based material)
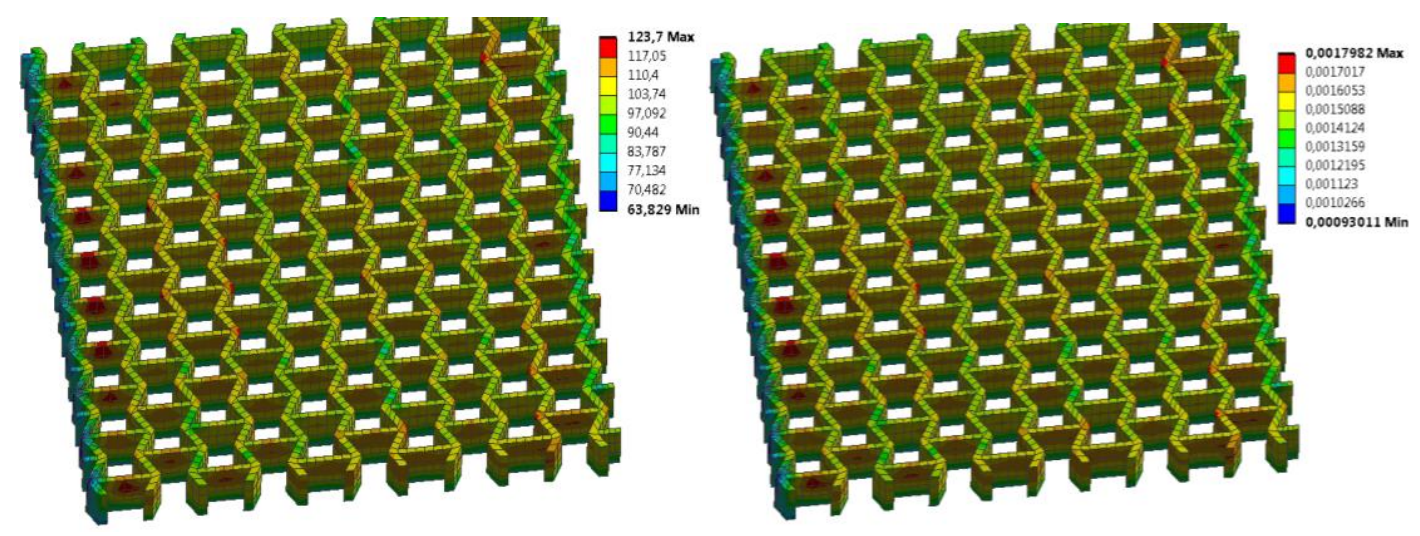

Fig. 6. Stress and strain values of auxetic structure $(1 \mathrm{~mm}$ thickness, made of aluminium - based material)

\section{DISCUSSION}

In the literature on the the statistics of injuries among riders, it is oftenshown that despite the use of head protection measures, i.e. an equestrian helmet, brain injuries occure in riders. The simulation confirms that currently used riding helmets, in which the damping layer is made of solid EPS foam, do not fully protect the user's head. The obtained distributions of stresses and strains of the human brain, compared to the literature data, show the possibility of brain injury.

In the second stage of the research in the simulation the structures of honeycomb, auxetic and mixed were used. In the available literature we can find the use of thoses layers in military helmets. In these helmets, the honeycomb and auxetic structures exhibit high impact damping properties, therefore they were used in the research. The simulations showed these structures are much better at absorbing the Energy caused by the rider falling off the horse and hitting the head against the ground. Research has shown that these structures can be implemented in equestrian helmets, which will significantly reduce the amount of brain injuries among riders. 


\section{CONCLUSION}

The paper presents a numerical model of the head structures including skull, brain and equestrian helmet. This model was used to dynamically simulate the rider's fall from the horse and hitting the head against the ground. The obtained results indicate the possibility of brain injury as a result of a fall. These tests were an introduction to the second stage, in which new damping structures were used which showed greater possibilities of absorbing Energy caused by hitting the head against the ground. Research has shown that equestrian helmets can be modified to provide greater protection to the rider. The use of honeycomb or auxetic structures in the attenuating layers of equestrian helmets can reduce the percentage of brain injuries among riders. The research also investigated the possibility of using a different material for the damping layer. The use of aluminium - based material clearly influenced the attenuation capabilities of the layers. They can ba an introduction to further research on the use of other materials that can significantly improve the damping properties and minimize nrain injuries occurring among riders.

\section{REFERENCES}

Baumgartner, D., Willinger, R., 2005. Numerical modeling of the human head under impact: new injury mechanisms and tolerance limits, IUTAM Symposium on Impact Biomechanics: From Fundamental Insights to Applications, Springer, 195 - 203, DOI: 10.1007/1-4020-3796-1_20.

Baumgmartner, D., Willinger, R., Shewchenko, N., Beusenberg, M.C., 2001. Tolerance limits for mild traumatic brain injury derived from numerical head impact replication, Proceedings of the International Conference on the Biomechanics of Impacts (IRCOBI), 353-355, DOI: 10.1533/ijcr.2003.0264.

Bourdet, N., Willinger, R., 2015. Head impact conditions in case of equestrian accident, Proceedings of the International Council on the Biomechanics of Injury (IRCOBI), 156-167.

Caserta, G. The use of honeycomb in the design of innovative helmets. 2012, DOI: $10.25560 / 9905$.

Deck, C., Willinger, R., 2008. Improved head injury criteria based on head FE model, International Journal of Crashworthiness, 13(6), 667-678, DOI: $10.1080 / 13588260802411523$.

Galbraith, J.A., Thibault, L.E., Matteson, D.R., 1993. Mechanical and electrical responses of the squid giant axonto simple elongation, Journal of Biomechanical Engineering, 115, 13-22, DOI: 10.1115/1.2895464.

Meredith, L., Ekman, R., Thomson, R., 2018. Horse - related incidents and factors for predicting injuries to the head, BMJ Open Sport \& Exercise Medicine, DOI:10.1136/bmjsem-2018-000398.

Miller, K., Chinzei, K. 2002. Mechanical properties of brain tissue in tension, Journal of Biomechanics, 35, 483-490, DOI: 10.1016/s0021-9290(01)00234-2.

Newman, J.A., 1986. A generalized acceleration model for brain injury treshold (GAMBIT), In: Proceedings of International Conference on the Biomechanics of Impact. Zurich, September, 121-133. 
Shreiber, D.I., Bain, A.C., Meaney, D.F., 1997. In vivo tresholds for mechanical injury to the blood-brain barrier, Proceedings of 41st Stapp Car Crash Conference, Lake Buena Vista, 277-293.

Willinger, R., Baumgartner, D., 2003. Human head tolerance limits to specific injury mechanisms, International Journal of Crashworthiness, 8(6), 605-617, DOI: 10.1533/ijcr.2003.0264.

Zheng, L., Yang, K.H., King, A.I., 2004. A proposed injury threshold for mild traumatic brain injury, J. Biomech. Eng, 126, 226-236, DOI: 10.1115/1.1691446.

Zhou, C., Khalil, T.B., King, A., 1995 I. A new model comparing impact responses of homogeneous and inhomo-geneous human brain, Proceedings of $39^{\text {th }}$ Stapp Car Crash Conference, San Diego, November, DOI: doi.org/10.4271/952714. 